\title{
Holy river no obstacle
}

\section{New Delhi}

IGNORING protests from environmental groups, India last week commissioned the controversial nuclear power reactor at Narora on the banks of the sacred Ganges in the state of Uttar Pradesh, $140 \mathrm{~km}$ east of Delhi.

The 230-MW reactor is the first of two units at India's fourth nuclear power station. Commissioning of the second unit at Narora has been put off until 1990 because of a lack of indigenous heavy water.

The twin reactors of the $\$ 500$-million Narora Atomic Power Station (NAPS) are based on the Canadian CANDU design that uses natural uranium fuel and heavy water as moderator and coolant. After Canada severed nuclear ties in 1974, India on its own built two CANDU at Kalpakkam near Madras in 1985. NAPS is the second totally indigenous station and, like the Madras reactors, is outside the control of the International Atomic Energy Agency (IAEA). The two USbuilt boiling-water reactors in Tarapur near Bombay and the two reactors near Kota in Rajasthan, built by Canada, are under IAEA inspection.

The siting of the new power station at Narora has been the subject of a bitter controversy between the Department of Atomic Energy (DAE) and environmental groups such as the Committee for Sane Nuclear Policy (Cosnup). While the Tarapur and Madras stations are sited near the sea, and the Kota reactors use cooling water from a lake, NAPS is the first Indian nuclear plant to be built near a major river. Although only make-up water will be drawn from the Ganges for the closed circuit cooling system, treated effluents will drain into the river, which is currently being cleaned up under a $\$ 250$ million 'Ganga action plan'.

Environmental groups have organized a 'Save Narora' campaign that is concerned about possible radioactive pollution of the Ganges, the life-line for 200 million Indians living in its basin. The new reactor at Narora is also the first reactor in India to be located in a seismic zone. Critics say the risk of radioactive pollution of the Ganges is heightened by the fact that the reactors are standing on alluvial soil only $50 \mathrm{~km}$ away from the Moradabad Fault. which was the centre of an earthquake in 1956.

These fears have been dismissed by DAE, which says the reactors have double containment systems and have been designed for automatic safe shutdown in case of earth tremors. The effluent treatment will be such that there will be 'zeroradiation discharge' into the Ganges. Critics, unconvinced, note that the extra money spent on making the plant earth- quake-proof could have been saved by siting the plant elsewhere. Earthquakeproof design considerations were mainly responsible for cost and time overruns. NAPS took 12 instead of 7 years to complete and its cost had doubled.

Ironically, commissioning of the new reactor at Narora will not add to India's installed nuclear power capacity but only bring it to the level that existed in 1986. Since then, output from the Tarapur reactors has been deliberately reduced to lessen the radiation dose to personnel there, and one of the two Kota units has been shut down due to a leak from the end plate of the reactor vessel. Attempts to plug the leak permanently have so far failed.

By the year 2000, India plans to produce $10,000 \mathrm{MW}$ or 10 per cent of total electricity demand from nuclear reactors. This would require commissioning of two or three reactors per year, an impossible task. Even if DAE could mass-produce reactors, it has to face a growing antinuclear lobby.

Opposition is already mounting against the nuclear station under construction at Kaiga, in the midst of rain forest in western Ghats, and the two $1,000-\mathrm{MW}$ reactors proposed to be built by the Soviet Union at Kodangulam on east coast of south India.

K. S. Jayaraman

\section{Soviet citizens not impressed by IAEA \\ London}

PLANS for a nuclear power and heating station in Gor'kii in the Soviet Union have roused considerable opposition from local inhabitants, who, in the aftermath of the Chernobyl accident, are concerned at the proposed siting of such a station only a few kilometres from the city centre. The Soviet nuclear planners have now agreed to call in experts from the International Atomic Energy Agency (IAEA) in Vienna, to assess the safety aspects. If the IAEA gives its approval, the station could begin supplying the city with heat next summer.

Twelve such stations were originally planned for the European part of the Soviet Union, with Gor'kii as the prototype. But the partly built station at Minsk is already being modified to operate on conventional fossil fuel, under local pressure. And Soviet public opinion, it seems, is not always ready to accept the IAEA experts as disinterested parties. Last autumn, when Dr Murray Rosen of IAEA tried to assure local people that the RBMK (Chernobyl-type) power station at Ignalina posed no threat, he received boos and catcalls.

Vera Rich
Pioneer in rocketry and radiation discovery

\section{Washington}

This year's Crafoord Prize has been awarded by the Royal Swedish Academy of Sciences to James Van Allen of the University of Iowa.

The prize, worth about $\$ 250,000$, is given annually in an area not covered by the Nobel prizes. This year's recipient is cited for his work in magnetospheric physics, his best-known accomplishment being the discovery in $\mathbf{1 9 5 8}$ of the 'Van Allen' belts, regions in the upper atmosphere in which charged particles of solar origin are trapped by the Earth's magnetic field.

Van Allen began his scientific career as an experimental nuclear physicist and became a pioneer of scientific rocketry, designing both novel detectors and the rockets that carried them. The Aerobee rocket was his work, and he was chief scientist for the Explorer I satellite, which found the radiation belts that carry his name. At the University of Iowa in the early $1960 \mathrm{~s}$, he and his pupils designed and built an important series of satellites.

These days, Van Allen is known as a critic of manned space exploration, believing it to be a scientifically unproductive extravagance.

David Lindley

\section{FOSSIL LOSS}

\section{Tourism falls victim to 'Tyrannosaurus'}

Tokyo

JAPAN'S only fossil to have acquired the exalted status of a national 'natural treasure' was toppled from its perch last week when word finally reached the press that the carnivorous Tyrannosaurus dinosaur discovered in 1976 at Mikasa City, Hokkaido, is actually a lizard, Mosasaurus.

Doubts about the fossil's identity have been circulating privately in the Japanese geological community for some time. Now that the truth has come out from the National Science Museum's Ikuo Obata, who made the original misidentification, Mikasa City (population 20,000) is stuck with a massive concrete replica of an erect Tyrannosaurus, a thriving industry supplying Tyrannosaurus souvenirs - from key rings to sweets and pickles - and a museum containing the fossilized head of what, after all, is a Mosasaurus.

City officials are deeply disturbed, saying that the Tyrannosaurus business is all they had to stop the outflow of people to big cities. The Cultural Agency, which granted the 'natural treasure' title says it is "studying the situation". Alun Anderson 